René Ballivián Calderón

\title{
NOTAS SOBRE LA FILOSOFIA DE LA INTUICION Y LA VIDA
}

72 UESTRA época es sin duda una época materialista. Los números y las máquinas parecen campear en todas las actividades de los hombres modernos. Los experimentos de física, las leyes de la economía, el engranaje financiero tienen en la mente de casi todos una importancia mucho mayor que las especulaciones filosóficas y los credos de religión. Sin embargo, en medio de este trepidar de motores y este amontonar de dinero, en medio de la actual civilización materialista, ha surgido, en pleno siglo XX, una filosofía romántica y metafísica, que se llama la filosofía irracionalista, y que, como su propio nombre lo indica, niega el primado de la razón en el conocimiento humano, colocando aguerridamente, por sobre ella, la intupición. Pero aun más, no solamente coloca lo racional en un plano secundario, sino que niega el materialismo y el naturalismo, todas aquellas cosas que restringen la libertad de lo que es vital en el individuo, haciéndolo un esclavo del mundo empírico.

No es, como se puede creer, una filosofía que huya 
temerosa de la acción y se entregue a vanos ensueños: es más bien una filosofía que en su absoluto indeterminismo invita a crear y a actuar, y que ve en el mundo, con su inmensa variedad de matices, con su peculiar encanto y con su constante fluir, un lugar propicio para que el hombre, por medio de la intuición, se ponga en contacto directo con su propia vida y con la vida entera del Universo, dando expresión a todo lo que tiene de nuevo y valioso.

Esta filosofía es, como he dicho ya, una filosofía metafísica, pero no niega lo real; es romántica, pero no se entrega al ensueño; es en suma una filosofía que si bien comulga en lo esencial con lo que fué la característica del Medioevo y de principios del siglo pasado, ha sabido adaptarse magistralmente a lo que es la característica de nuestra época, la acción. Espectáculo único es ver surgir, en este mundo de materialismo, pensamientos metafísicos, románticos y espirituales.

Si Descartes levantó en macizo pedestal a la razón y si Kant produjo una crítica de esa misma razón. Bergson, corifeo del nuevo pensamiento filosófico, coloca por sobre ella la intuición, librándonos así de largo cautiverio. Acepta, empero, tras del subjetivismo que defiende, un todo en que habrán de fundirse las diversas individualidades. Es pues una filosofía de cultura y por ende conserva todo su brillante arreo espiritual, metafísico y religioso.

Dios es para esta filosofía el ser único, el principio de todo acontecer, y ve en la religión el punto culminante de la vida espiritual humana, aunque admite que las actuales doctrinas son un tanto anticuadas y estrechas. Aun más, afirma que la religión es indispensable para la verdadera vida creadora. Cuán discordantes con las tendencias de la época actual suenan estos preceptos, que parecen traer consigo olvidadas esencias de Edad Media, de Santo Tomás, de la teología grave y señorial. Entre las modernas escuelas 
filosóficas es esta la que mayormente invita a reposar en su seno. Hace el efecto de un viejo caserón dotado de las comodidades y lujos modernos, que conserva, empero, lo poético y halagador de su historia.

Los conocimientos científicos no tienen para la filosofía irracionalista el máximo valor. Radica éste más bien en la vida, considerada como fiel expresión de las íntimas fuerzas espirituales. La especulación filosófica deberá partir de la experiencia vital inmediata, la cual no ha de influenciarse por los conceptos abstractos que cría el intelecto.

El pensamiento racional, al percatarse cada momento de lo impotentes que son sus fuerzas, de lo restringido que se hace por ende el campo de sus experimentos, lleva fatalmente a la infecundidad, terminando en el anquilosamiento, en el escepticismo, en la inacción; en cambiolo intuitivo, en su eterno traer de lo inconsciente a la conciencia fuerzas nuevas y nuevos deseos, lleva a los hombres a la acción con plena fe en el valor de la vida y del Universo, encendiendo los espíritu con un benéfico optimismo, que es el principio de salvación para los pueblos y las culturas. La vida así entendida es muy superior a todo lo mecánico, y a toda la concepción mecánica que de ella se forma el frío y escueto intelecto. Es el hombre, antes que nada, espíritu; toda vez que obra como materia obra negativamente. Bergson-si mal no recuerdo-observa que cuando una persona resbala en la acera o tropieza con un poste, obra como materia y es por eso que causa hilaridad. Debemos, pues, librarnos de todo lo que sea puro materialismo, porque nuestro espíritu, nuestra propia vida, está muy por encima de él. Busquemos los goces del espíritu que nos enseñarán más y mejor. No es necesario negar la materia, sino darle el puesto que le corresponde en el Universo, donde necesariamente rige lo espiritual.

La diferencia existente entre las antiguas tendencias 
filosóficas naturalistas y materialistas, guiadas por la razón, y la moderna corriente filosófica irracionalista que aspira a conocer el Universo por medio de la intuición, es la misma que existe entre la pintura impresionista y la expresionista. Mientras la primera se ocupa de reproducir impecablemente el objeto, la segunda tiende a interpretar éste en el lienzo, de acuerdo con la idea que de él se ha formado el sujeto.

Luego la vida es fluir, un constante amontonar de sensaciones, una sevolución creadora» y a esta tendencia a crear, a existir, la llama Bergson célan vital». Su última esencia, ni los conceptos, ni el intelecto, ni la razón, pueden llegar a percibirla; lo único capaz de comprender y expresar ese fluir constante es lo intuitivo. Veamos, pues, algunos de los rasgos característicos de esta moderna filosofía de la intuición y de la vida.

\section{$\star$}

Hemos hablado mucho ya de intuición y sin embargo aun no se ha definido lo que esa palabra significa, Vamos para ello donde Bergson. ¿Intuición», según él, *es una penetración artístico-mística en lo absoluto». ¿Quiénes son pues, los hombres de mayor intuición? Sin duda los poetas, los músicos, los pintores, en una palabra, los artistas. Aquellos hombres que por medio de la acción y de un constante buscar la esencia de la vida sin ayuda de conceptos, se ponen en inmediata unión con lo que tiene el Universo de real y absoluto. Aquellos que buscan el símbolo. Lo que mejor representa a la intuición es el símbolo. El símbolo es la unidad por medio de la cual hallan expresión un gran número de sensaciones y de hechos diversos, es la unidad que explica lo individual y el todo, sin dejar 
escapar la esencia de verdad que cada cosa en sí posee. El símbolo no está formado de conceptos: es la realidad misma. La intuición sólo se expresa por el símbolo.

El año que marca el nacimiento de la nueva filosofía es el de 1889, año en que Bergson publica su Essai sur les données inmédiates de la conscience; ocho años después sigue Matiere et Mémoire, y por fin en 1907 sale a la luz pública su obra maestra: L'Evolution créatrice. Ya por entonces Bergson, que era profesor en el Colegio de Francia, había ganado fama mundial; sus conferencias eran atendidas por lo más selecto de la aristocracia y del mundo intelectual de París. En 1914 vió su labor filosófica y literaria coronada con el mayor de los éxitos, pues en aquel mismo año sus libros fueron anotados en el "Indice» y la Academia de Francia le hizo uno de sus inmortales.

En su Essai sur les données inmédiates de la conscience describe su propia vida espiritual; en Matiere et Mémoire investiga la percepción y el recuerdo, y por último en la Evolution créatrice, donde encontramos lo más acabado y original de su filosofía, estudia la evolución universal, que es la esencia y significación de la vida.

Justamente cuando el factor tiempo nace como cuarta dimensión en la física, la filosofía aprecia, por su parte, la importancia de su papel en el conocimiento humano. Mas el tiempo en la filosofía de Bergson no tiene el mismo sentido que en la física. El intelecto concibe cada parte del curso temporal como momentos iguales exteriormente yuxtapuestos. Esto es materializar lo espiritual. «Nos hallamos por naturaleza inclinados al materialismo», piensa Bergson - él mismo fué en su juventud discípulo y admirador de Spencer-, porque, declara, pensamos siempre en términos de espacio, pero el tiempo es tan fundamental como el espacio, y es el tiempo, sin duda, lo que con- 
tiene la esencia de la vida. El tiempo es duración (durée réelle), acumulación, eterno progresar del pasado hacia el futuro. El yo varía constantemente, y este fluir de la vida, está «duración real», permanece inaprehensible para los conceptos del intelecto, cuya idea de tiempo es mecanicista, convirtiéndola, por lo tanto, en espacial y vacía. Pero, diremos nosotros, para citar sólo un ejemplo, el cinematógrafo, que pertenece al mundo de la mecánica, hace aparecer ante nuestra vista como realmente vivientes $\mathrm{y}$ animados cuadros yuxtapuestos. He aquí que la ciencia ha dado fiel expresión a la continuidad de la vida, será el pensamiento de muchos; mas eso que percibimos como lleno de acción y de vida, son, al fin, una serie de instantáneas fotográficas tomadas sucesivamente, que al ser presentadas con rapidez ante el telón parecen hallarse animadas. Por el contrario, es este experimento el que mejor nos sirve para ilustrar la concepción que del tiempo se forma la mecánica; ve ésta, ante todo, una serie de cuadros yuxtapuestos, mas la esencia que une cada cuadro y que da unidad al fluir cósmico no alcanza a ser percibida. Bien dice Bergson que «los conceptos científicos semejan una red por entre cuyas mallas escapa la realidad, que está en continuo movimiento».

\section{$\star$}

Al negar que la vida es un proceso mecánico, no se puede concebir el determinismo, pues cada momento de nuestro yo tendría que ser el resultado del momento anterior, y así paulatinamente, hasta que llegaríamos a la nebulosa primera como esencia y causa de todo acontecer. ¿Por qué no aceptar que el momento presente depende de las decisiones y del crear de nuestra voluntad $y$ de nuestra mente? Si falso es el 
determinismo, falsa también es la concepción intelectual del indeterminismo, en tanto que desea explicar la forma en la cual el yo actúa.

El yo-dice Bergson-vive en sus vacilaciones y oscilaciones hasta que la acción se desprencie de él como la fruta madura del árbol.

El indeterminismo proviene de lo consciente, que por medio de la memoria evoca en una dada circunstancia todas aquellas percepciones de su existencia anterior que mejor concuerden con las experiencias del momento presente, y procura, al mismo tiempo, aconsejarnos aquella decisión que sea la más ventajosa. Este eterno decidir y escoger en el hombre hace que su existencia sea superior a la de los animales, cuya vida es de eterna indiferencia y de tranquilidad absoluta. Toda decisión forma en sí un acto creador, y es también un fuerte estímulo para la propia personalidad. Jamás nos sentimos tan poderosos y tan pletóricos de vida como después de haber llevado a cabo una gran decisión. Por medio de ella hemos puesto en juego lo que tenemos de vital y de esencial. Todas las fuerzas del espíritu, aunque por largo tiempo dormidas en lo más íntimo de nuestro ser, parecen surgir a la realidad y recordarnos la importancia de nuestro papel y la superioridad de nuestra condición en el Universo.

Hecho innegable es que todo hombre, todo hombre inteligente por lo menos, huye con horror de los trabajos mecánicos y monótonos, en busca de lo que fluye constantemente, de lo que evoluciona. Le atrae sobremanera aquello que implique novedad, todo lo que sea salir del marco establecido de las cosas. Le seduce lo nuevo, 10 imprevisto. ¿Qué es esto sino una formidable negación a la concepción mecánica de su existencia? El hombre es espíritu y busca dones espiri- 
tuales porque son los que más plenamente le satisfacen. El hombre no es en grado sumo materia, y no obra, por lo tanto, bajo el determinismo inherente a la materia. Le seduce la acción y lo nuevo, las ideas nuevas, los paisajes nuevos, los pueblos nuevos. Desea ante todo sentirse libre y henchido de su propio ser. De ahí esa admiración que muchos sienten por las existencias aventureras, los viajes y hasta las guerras, que serán todo lo horribles que se quiera, pero dan lugar para que el hombre, con regio acompañamiento de bombas y de sables, vuelva realidad una porción de instintos y deseos largo tiempo refrenados; las guerras son, muchas veces, un desahogo para los pueblos. De ahí ese encanto que siempre ha tenido la travesura, el experimento con objetos y conceptos nuevos. El hombre tiene sed de dominio, quiere ver su propia existencia palpitar en las cosas que le rodean, dar salida a sus impulsos, expresar en una forma u otra su concepción del Universo, sentir que es él lo actuante, lo absolutamente contrario a la materia, o sea pasividad y quietud.

Ha sido negada la primacía del materialismo y determinismo y hemos aceptado como esenciales los dones del espíritu; valorízase, pues, *lo vital».

Vital es aquello que progresa, es lo que avanza, es lo antagónico de materia; mientras lo material constituye el descenso, el aniquilamiento, la vida es un eterno construir, un eterno deseo de procrear-como dijera hace veinticuatro siglos el Buda-; es por último lo contrario de inercia. Este constante crecer y avanzar del Universo, esta «evolución creadora», se lleva a cabo por un aliento vital que le es inherente y que se llama «élan vital». El «aliento vital» originario es Dios, según la filosofía irracionalista.

En los primeros tiempos todo era quietud, reposo, mas pronto la vida no pudo soportar esa inercia digna tan sólo de las plantas o de la materia, y en busca 
de aventuras huyó de la seguridad hacia el constante peligro de la existencia libre.

En la evolución de las sociedades humanas-dice Bergsony de las diversas individualidades, el éxito ha sido para aquellos que han aceptado los mayores peligros.

El determinismo y la materia forman el círculo ya dado, mientras que la acción rompe ese círculo y busca nuevos horizontes. La filosofía metafísica y romántica de Bergson es pues una magnífica invitación a actuar y a crear, a poner en juego por sobre todo nuestros propios valores vitales, para tomar parte así en esa constante evolución creadora, cuya última esencia escapa a los conceptos y al intelecto mismo y que sólo se expresa por el símbolo.

Mas la idea que de lo vital tiene la filosofía irracionalista es un tanto mística. Niega los conceptos culturales pero acepta un Dios, un fin hacia el que se mueve todo. Es, en cierta manera, un retorno a la Edad Media. Coloca en primer plano lo vital en el individuo, pero ese vitalismo debe ir encauzado hacia un símbolo o una realidad exterior, Dios en este caso, pues según la filosofía de la intuición, Dios es el centro del organismo cósmico, el principio de toda actividad, el origen de todas las cosas. Semejante concepción filosófica no es del todo afín con el actual momento histórico, que es de caos y desorientación, pues los valores culturales, y aun más, las ideas místicas de un «todo", ha desaparecido; al comenzar nuestro propio siglo los unos, en el Renacimiento los otros. En la época actual existe el vitalismo como principio de toda actividad y de toda volición, pero esa volición vitalista no tiene un fin, un todo al que ha de dirigirse. El culturalismo encauza las actividades de los hombres hacia ciertos conceptos: lo bueno, lo bello, lo justo y por ende a las ciencias, a las artes, a las leyes; bus- 
cando siempre una cosa en torno nuestro, un algo trascendente de nosotros mismos por quien trabajar, y en aras del cual sacrificar nuestras fuerzas intelectuales y hasta físicas.

Es el hecho pues, como dice Ortega y Gasset, \&que hasta el presente la vida no ha sido consagrada como principio capaz de ordenar en torno suyo las demás cosas del Universo». Las ciencias, las artes, las religiones, etc., son blancos hacia el que se dirigen las actividades de los hombres con el objeto de buscar verdades, sean o no de beneficio para el individuo, aunque cabe notar que la idea de que verdad es todo aquello que reporta bienes al hombre se llama pragmatismo, y es una orientación filosófica que cuenta actualmente con muchos exponentes; Dewey, James, para citar sólo dos.

Si hemos de comprender plenamente la vida «hay que saltar fuera de ella», como dice Ortega y Gasset en su magistral obra El tema de nuestro tiempo, «y desde el exterior verla fluir». No es la vida aprehensible para nosotros mismos, pues somos lo actuante; si deseamos entenderla plenamente se hace necesario retraernos a lo profundo de nuestro ser. Desde allí podremos, en parte, apreciar esa fuerza que en vez de ser dominada habrá de dominar los elementos cósmicos. Es innato en el hombre establecer jerarquías, y si hemos de comparar, como dice el filósofo de El tema de nuestro tiempo, cla vida más doliente y sórdida con la piedra más perfecta notamos al punto la superior dignidad de aquella».

Algunos hombres de genial intuición en el siglo XIX anticiparon la época actual. La época de los valores inmannente a la vida. Esta época en que cada individualidad es un fin, en que la vida es vivida por la vida misma, sin que existan cosas y abstracciones trascendentes de ella, hacia las que debe encauzar sus activiclades y voliciones. Negado un «todo» que sea a la Atenea. -28 
vez un fin para las fuerzas vitales de los hombres, quedarán estas mismas fuerzas vitales como principio de toda actuación. Es decir, cada individualidad transfórmase en un todo; naciendo el caos y la desorientación. Nuestra época es pues una época no solamente anti-cultural sino que es acultural. Es en suma una época individualista, una época que ha podido crear y amparar orientaciones filosóficas tales como la fenomenológica. La fenomenología estudia cada objeto, cada manifestación del Universo separadamente, como algo único y absoluto, como un fin en sí. Actualmente ha perdido eficacia todo el sistema de valores que hace sólo un cuarto de siglo veneraba religiosamente el mundo occidental. La política es siempre una actividad importante, pero fué creada para los hombres, no los hombres para ella; el arte es algo muy bello cuando es bueno, pero también fué ideada para solaz de los hombres, y así todas estas poderosas entidades culturales de los dos o tres siglos que anteceden al nuestro, no son relegadas al olvido, o simplemente negadas, sino que por sobre ellas habrá de colocarse la vida humana, y por ende, serán estudiadas y comprendidas de acuerdo con su rango en los valores del Universo.

Es indudable que la filosofía irracionalista atribuye a la intuición poderes que no tiene, y que por otro lado niega al intelecto muchas de sus evidentes cualidades. Alguien ha dicho, y quizá con razón, que la filosofía bergsoniana pudo haber buscado en una superior inteligencia el medio por el cual debemos de investigar la realidad del Universo. Mas, sea como fuere, Bergson ha lanzado un magnífico reto al materialismo, que tenía ya cautivadas las mentes de casi todos los hombres occidentales y que, sin duda, hoy mismo cuenta en el campo de las especulaciones filosóficas, con muchos partidarios y descendientes de Spencer, Comte, Stuart Mill, ya sea un Vaihinger o un Mach; la idea cultu- 
ralista perdura en Rickert, Windelband, el intelectualismo en Cohen, la religión cuenta con Eucken, Troltsch, Rodolfo Otto, Max Scheler, Francisco Brentano. En cambio los verdaderos exponentes de nuestra época son, a mi modo de ver, Bergson (en tanto que niega el materialismo), Spengler (en tanto que anuncia la decadencia de nuestra cultura), Hüsserl, Keyserling, y un español: José Ortega y Gasset. Lo que mejor simboliza el actual momento es el nuevo arte, tan lleno de optimismo, de risas y de vida. Por fin parecen comprender los hombres que el arte fué ideado para entretener a ellos mismos y lo han despojado, por consiguiente, de todo ese aspecto de seriedad y tragedia que le caracterizaba hasta hace sólo un cuarto de siglo.

No debemos olvidar tampoco a los precursores de la época actual. Al genial Nietzsche, que se preguntó qué había de dominar en el mundo, si la ciencia o la vida, y repuso con toda la fuerza que le era característica, que la vida habría de dominar en el Universo; y también al poeta de Weimar, Goethe, quien en cierta ocasión exclamó:

Cuanto más lo pienso, más evidente me parece que la vida existe simplemente para ser vivida.

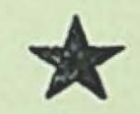

Ha llegado pues, el momento en que la vida ha de ser considerada como principio ordenador de todo el vasto organismo cósmico, y en torno de la cual habrán de girar las abstracciones culturales, todas las cosas trascendentales de ella, todos los ideales que largo tiempo han sido pensados como fines, cuando son tan sólo medios para llegar a la realización de una verdad superior y única: el hombre. 